\title{
RESSONÂNCIAS POÉTICAS: \\ TRADUÇÃO CRIATIVA A PARTIR DA LITERATURA PARA O TEATRO
}

\author{
Poetic resonances: \\ creative translation from literature to theater \\ Danilo França do Nascimento \\ Centro Federal de Educação Tecnológica - CEFET- MG
}

Resumo: Este artigo analisa a vida e obra de Clarice Lispector em relação com o espetáculo teatral Prazer, da Cia. Luna Lunera. Como principal aporte teórico para este estudo, optou-se pela Tradução Criativa, que não tem como objetivo completar o original, mas sim reverberá-lo, criando com ele uma ressonância de sentidos poéticos. É nesse intuito que se realizam as análises dos objetos deste estudo.

Palavras-chave: Tradução Criativa; Prazer, Clarice Lispector.

Abstract: This paper analyzes the life and work of Clarice Lispector in relation to the theatrical spectacle Prazer, by Cia. Luna Lunera. As the main theoretical contribution for this study, Creative Translation was chosen, that it is not understood to complete the original, but rather to reverberate it, to create with it a resonance of poetic meanings. It is in this bias that the analysis between the objects of study is realized.

Keywords: Creative Translation; Prazer, Clarice Lispector. 


\section{Prazer $^{1}$ e Clarice Lispector}

O espetáculo teatral Prazer, da Companhia Luna Lunera, sediada em Belo Horizonte (MG), estreou no final de 2012, após um intenso processo criativo desde $o$ ano anterior. $\mathrm{Na}$ época, os artistas da companhia chamados de lunos - avaliaram o que foi realizado nos últimos dez anos, quando decidiram montar um novo espetáculo, com o mesmo tipo de processo criativo que já haviam experimentado anteriormente na criação de outros espetáculos. Essa criação, realizada com base no Processo Colaborativo, refere-se ao trabalho de direção e dramaturgia compartilhadas, quando cada ator-codiretor desenvolveu o seu próprio projeto de direção com os demais. Foi a partir disso que surgiu a ideia para a montagem de Prazer, que contou com atuação e codireção de Cláudio Dias, Isabela Paes, Marcelo Souza e Silva, Odilon Esteves, a codireção de Zé Walter Albinati, e a orientação dramatúrgica de Jô Bilac.

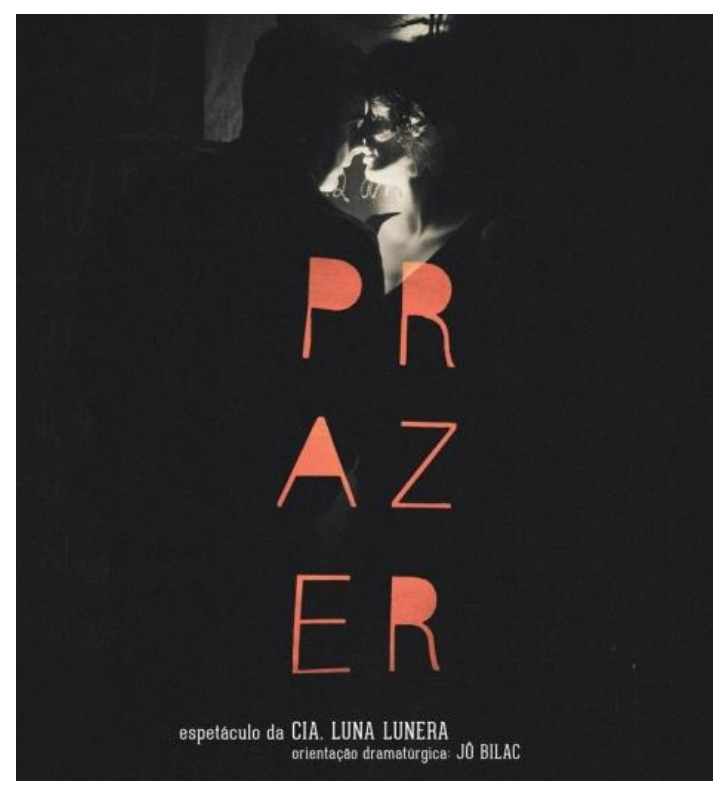

Figura 1: Folder do espetáculo Prazer $^{2}$

1 Espetáculo teatral, com gravação em vídeo. Belo Horizonte, dezembro de 2013. Disponível em: <https://www.youtube.com/watch?v=5x8-KYhYIW4>. Acesso em 10/05/2015.
Ainda no início do processo criativo do espetáculo, os lunos tiveram como fonte de inspiração os textos de Clarice Lispector, sobretudo o romance Uma aprendizagem ou o livro dos prazeres. Ao longo do processo, por conseguinte, os atores tiveram a liberdade de percorrer a vida e obra da escritora de acordo com suas próprias sensibilidades, além de ter sido igualmente livre o uso de diversos outros materiais em prol da criação do espetáculo.

Uma aprendizagem conta uma história simples, porém potente. Clarice escreveu nesse livro a procura individual e compartilhada da aprendizagem entre duas pessoas: Lóri e Ulisses. Ambos estão vivendo momentos diferentes um do outro, e por isso mesmo que recebem e doam constantemente entre si. Lóri se encontra fechada ao mundo, e se vê ansiosa por isso. Ulisses não tem muito mais o que provar a ninguém, mas deseja aprender. Ambos estão à procura de algo, ainda que não saibam exatamente do que se trata. No livro, Lóri e Ulisses se completam sem se fechar, cada um a seu tempo, pois estão em constante processo.

De modo similar, Prazer mostra a história de quatro amigos (Camilo, Isadora, Marcos, Ozório) que se reencontram em um país estrangeiro, sem defini-lo exatamente. Eles se veem envoltos em momentos distintos um do outro, porém, no decorrer do espetáculo, tornase evidente que eles estão vivenciando dilemas e angústias semelhantes em suas vidas. Apesar disso, os quatro amigos têm a coragem de procurar pelo prazer de viver. $\mathrm{O}$

\footnotetext{
2 Disponível em: <http://cialunalunera.com.br/espetaculos/prazer/>.
} Acesso em: 5/11/2014. 
apesar de revela-se o mote desses quatro seres em processo (constante formação).

Para esta pesquisa, a escolha por Clarice Lispector se dá principalmente por dois motivos: sua importância para o cenário literário do Brasil desde a década de 1940, e a teatralidade - no sentido de potencialidade cênica - contida em suas obras. Mais de setenta anos após o lançamento de seu primeiro livro, a escritura de Clarice ainda é objeto de estudo em diversos livros, artigos, teses e dissertações, além de muitos espetáculos teatrais realizados a partir de sua vida e obra. Já a escolha de Prazer se dá tanto pela representatividade da Cia. Luna Lunera no cenário teatral de Minas Gerais, quanto por ser Clarice Lispector uma importante fonte de criação desse espetáculo. A Companhia é considerada como uma das principais referências do teatro contemporâneo em Minas Gerais, devido ao seu processo criativo investigativo, tendo como foco o trabalho dos atores-criadores.

Busca-se neste artigo, por conseguinte, analisar a linguagem da obra clariceana em relação com Prazer, tendo como instrumento de análise o processo criativo dos atorescodiretores da Cia. Luna Lunera e os possíveis efeitos de sentidos que são lançados ao espectador, em relação com o universo de Clarice Lispector.

\section{Tradução Criativa}

Uma das vertentes teóricas que se propõe neste trabalho, no que tange à interpretação semiótica sobre o espetáculo Prazer, em relação com o universo clariceano, a Tradução Intersemiótica se mostra um adequado aporte teórico, conforme é explanado nas páginas seguintes. No entanto, antes de abarcar esse conceito em si, faz-se necessário primeiramente considerar o que é Semiótica e, por conseguinte, definir o termo signo.

A Semiótica se refere a uma ciência dos signos, da significação e da cultura. Entre as diversas correntes de estudos dos signos, uma muito conhecida é a teoria Semiótica desenvolvida pelo norte-americano Charles Sanders Peirce, que é utilizada como base para os estudos da semioticista brasileira Lucia Santaella (2010). Segundo a autora, a Semiótica não possui um objeto de estudo determinado - quando nesse caso encontramse instrumentos concretos de pesquisa a serem aplicados. Por isso que a Semiótica se difere de outras ciências especializadas, tais como são a física ou a economia, por exemplo.

A Semiótica, desse modo, pode ser considerada como uma ciência de características profundamente gerais $e$ abstratas.

Ainda de acordo com estudos de Santaella (2010), o signo refere-se a qualquer coisa ou espécie que representa uma outra coisa (objeto do signo), que por sua vez produz um efeito interpretativo (interpretante do signo) em uma mente. Para ilustrar esse conceito, a semioticista afirma que "um vídeo [...] sobre o desmatamento da região amazônica é um signo que tem por objeto a região retratada no vídeo. Os efeitos interpretativos que o vídeo produz em seus espectadores é o interpretante do signo" (SANTAELLA, 2010, p. 9). Nesse exemplo, torna-se perceptível que os efeitos interpretativos (interpretantes) ligam-se diretamente com a maneira pela qual um signo representa o seu objeto. 
A Tradução Intersemiótica, segundo Julio Plaza (1987), refere-se ao pensamento em signos, um constante movimento de sentidos. Conforme se entende que o pensamento existe por meio dos signos, então esse já se encontra dentro da cadeia semiótica, sendo, portanto, qualquer pensamento uma tradução. Plaza (1987) ainda define 0 ato de traduzir criativamente como uma ampliação dos possíveis sentidos de uma obra original, e/ou colocar em foco um sentido especificamente: "traduzir é [...] repensar a configuração de escolhas do original, transmutando-o numa outra configuração seletiva e sintética" (PLAZA, 1987, p. 40). Desse modo, uma tradução não tem como objetivo completar o original, mas sim reverberá-lo, criar com ele uma ressonância de sentidos.

Nessa perspectiva, Thaís Diniz (1994) elucida que $o$ ato de traduzir envolve bem mais que a incorporação de um texto-fonte por um texto traduzido, mas sim um texto que é referido (afetado) por outro, mantendo desse modo uma relação (representação) entre si. Para a pesquisadora, esta relação entre os textos refere-se ao objeto de estudo da Tradução Intersemiótica. Entende-se que por meio da linguagem se produz sentidos, sendo possível significar algo a partir, por exemplo, de movimentos, gestos, expressões artísticas, dentre diversas outras atividades semióticas com os seus próprios sistemas de sentidos. Assim, traduzir uma linguagem artística para outra - por exemplo, do teatro ao cinema significa entender o outro texto enquanto um signo em um diferente sistema semiótico: "a tradução se define, pois, como um processo de transformação de um texto construído através de um determinado sistema semiótico em um outro texto, de outro sistema" (DINIZ, 1994, p. 1003). Pode-se então afirmar que um texto traduzido é uma obra independente e autônoma, mas que ao mesmo tempo possui uma forte ligação com o seu texto-fonte.

O conceito de Tradução Criativa também se mostra interessante para este artigo, conforme foi desenvolvido pelo crítico e poeta Haroldo de Campos (2010). Ele defende a ideia de que toda tradução refere-se a uma recriação, que possui uma autonomia apesar de ser recíproca à obra original. A Tradução Criativa, desse modo, refere-se a uma criação paralela, pois não é traduzido somente o significado, mas traduz-se o próprio signo. Por isso, quanto mais dificuldades encontra-se para a recriação, mais aberto criativamente se encontra tal processo. Campos (1969) ainda defende que a tradução de um poema - ou qualquer outra expressão artística - não possui como principal função reconstituir a mensagem, mas sim reconstituir uma estrutura de signos que esta mensagem possui. Refere-se a uma tradução perante o signo da invenção.

Portanto, na busca por um termo para se investigar o processo criativo de Prazer, a partir do universo clariceano, a palavra tradução se mostrou mais pertinente. Pois, entende-se que 0 ato de traduzir proporciona uma reverberação - assim como um eco - de múltiplos sentidos entre obras artísticas, em que uma obra traduzida se mostra autônoma, mas que ao mesmo tempo se relaciona reciprocamente com a estrutura de signos que serviram como inspiração criativa. O termo tradução, desse modo, possui a concepção de ser uma transposição criativa, em que ocorre um constante intercâmbio de um sistema de signos para outro, de uma arte para outra arte. No caso desta pesquisa, refere-se a um intercâmbio da arte literária para a arte teatral.

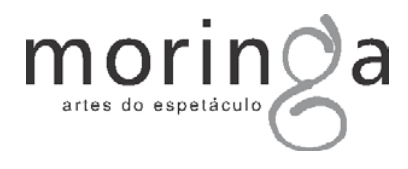


Vale também esclarecer que não se pretende realizar neste artigo uma análise semiótica rigorosa de como os signos agem, de uma maneira lógica e matemática, o que se considera limitador frente à expressão artística. Antes disso, os estudos semióticos foram aqui utilizados enquanto importante contribuição para o aprimoramento do olhar crítico e analítico do pesquisador frente aos objetos de estudo.

Os artistas da Cia. Luna Lunera elucidam que não houve a intenção de adaptar diretamente uma ou mais obras literárias de Clarice Lispector. Eles afirmam que a vida e obra da escritora foram utilizadas como fonte de inspiração e alimento poético para a criação do espetáculo, "possibilitando que cada um dos criadores oferecesse como material cênico inicial as reflexões, afetos e movimentos internos gerados por estas leituras"3.

A respeito do termo adaptação, conforme foi citado pelos lunos, vale considerar a sua definição, realizada por Patrice Pavis (2005), em três sentidos: o primeiro refere-se à transposição de um gênero para outro, como, por exemplo, a adaptação de um romance para uma peça teatral. $O$ segundo sentido refere-se ao trabalho dramatúrgico que se realiza a partir de um texto que já foi escrito para ser encenado. Por fim, o terceiro sentido refere-se a "uma tradução que adapta o texto de partida ao novo contexto de sua recepção com as supressões e acréscimos julgados necessários à sua reavaliação" (PAVIS, 2005, p. 10).

3 Disponível em: <http://cialunalunera.com.br/espetaculos/prazer/>. Acesso em 03/03/2014.
Tradução para a cena não significa simplesmente a "tradução interlingual do texto dramático", tampouco "uma busca de equivalências semânticas de dois textos, mas uma apropriação de um texto-fonte por um texto-alvo" (PAVIS, 2005, p. 412). Desse modo, o terceiro sentido de adaptação segundo o teatrólogo - de ser uma tradução (apropriação) - se mostra mais adequado ao propósito deste trabalho, pois são investigados aqui os textos-fonte de Clarice apropriados pela Cia. Luna Lunera, o processo criativo realizado para a transformação no texto-alvo, e o texto-alvo em si (o espetáculo Prazer). Mostra-se, assim, mais uma vez adequado utilizar o termo tradução, em detrimento do termo adaptação e de outros, para que não haja conflito de sentidos, conforme já mencionado.

\section{Clarice e Prazer: ressonâncias poéticas}

A propósito da utilização da vida e obra de Clarice Lispector na criação de Prazer, a atrizcodiretora Isabela Paes (2013), em entrevista concedida a esta pesquisa, elucida que todo o trabalho criativo se desenvolveu a partir de uma contaminação entre os atores e o universo clariceano:

Quando se fala de Clarice no meio
acadêmico, já se tem todo um
entendimento dos porquês, dos não
porquês, do que é. E nesse processo não
houve esse lado. Não estudamos Clarice
academicamente. Mesmo que líamos as
biografias e os trabalhos acadêmicos
sobre ela, isso acontecia porque estava
reverberando em nós, nos contaminando.
Começamos então com Uma
aprendizagem ou o livro dos prazeres de
Clarice, depois podíamos percorrer toda a
sua obra. Cada ator-codiretor escolhia e 
lia o máximo que pudesse, mas que sentisse como parte. Definimos que seriam somente as obras de Clarice Lispector. (PAES, 2013, s/p)

A atriz ainda afirma que, devido à imersão dos atores-codiretores nas obras de Clarice durante a montagem de Prazer, eles também se interessaram pela vida da escritora, além de estudos sobre ela. Contudo, não era do interesse dos artistas explicar Clarice Lispector no palco. A escritora foi entendida como uma das colaboradoras do processo criativo. Fica decerto evidente o desejo da Cia. Luna Lunera em ser afetada pelo universo clariceano, exercendo assim uma influência cocriativa no processo de montagem de Prazer.

Por meio das informações próprias de cada ator-codiretor, em conjunto com diversas outras informações provenientes da vida e obra de Clarice Lispector, criou-se o espetáculo. É perceptível tal relação quando Paes (2013) relata que as obras e informações sobre a escritora reverberaram nos artistas a ponto de os contaminar, considerando-a então como uma cocriadora do espetáculo.

Torna-se, assim, possível entender que, na tradução criativa realizada no espetáculo Prazer, a relação incerta entre Lóri e Ulisses de Uma aprendizagem dá lugar ao reencontro de quatro amigos: Camilo, Isadora, Marcos e Ozório. O nome Ulisses continua no espetáculo, mas como um cachorro (em forma de arte digital) cujo dono, Marcos, tenta the ensinar uma língua inventada:

MARCOS: (conversa com o cachorro Ulisses, projetado na parede) Dacoleba, Tutiban. Ziticoba, letuban. Zozuleba, lebajan? Atotoquina, atotoquina, zefiram. Jetobabe, jetuban! Deus do céu, não adianta eu tentar... você não presta atenção em nada do que eu falo. Eu posso falar com você em qualquer língua, até na língua do $P$ : vopocêpê épé inpinsupuporportápávelpel. (37:23min) ${ }^{4}$

Essa língua inventada se revela, decerto, uma tradução criativa do cachorro da personagem clariceana Ângela Pralini, também chamado Ulisses, presente no livro Um sopro de vida. Em relatos, a personagem Ângela procura decifrar o seu misterioso cachorro, adentrando na plenitude de ser-vivo cuja qualidade ele recebe: "o meu cão me ensina a viver. Ele só fica 'sendo'. 'Ser' é a sua atividade. E ser é minha mais profunda intimidade" (LISPECTOR, 1978, p. 63). Nesta procura de entender seu bicho, assim como acontece com Marcos, de Prazer, Ângela inventa uma língua: "eu sei falar uma língua que só o meu cachorro, o prezado Ulisses, meu caro senhor, entende. É assim: dacoleba, tutiban, ziticoba, letuban. Joju leba, leba jan? Tutiban leba, lebajan. Atotoquina, zefiram. Jetobabe? Jetoban" (LISPECTOR, 1978, p. 64, 65).

Clarice Lispector, já nos anos finais de sua vida, também teve um cachorro chamado Ulisses. Sua relação com o seu bicho era tão íntima que a escritora até mesmo o colocou como narrador do livro infantil Quase de verdade. Neste, o desobediente Ulisses conta a sua história latindo, sendo a sua dona, Clarice, a responsável por transcrever para a língua dos humanos: "eu fico latindo para Clarice e ela - que entende o significado de meus latidos escreve o que eu the conto. [...] Sou um pouco malcriado, não obedeço sempre,

\footnotetext{
${ }^{4}$ Disponível em: <https://www.youtube.com/watch?v=5x8KYhYIW4>. Acesso em 10/05/2015.
} 
gosto de fazer o que eu quero, faço xixi na sala de Clarice" (LISPECTOR, 1999, sp).

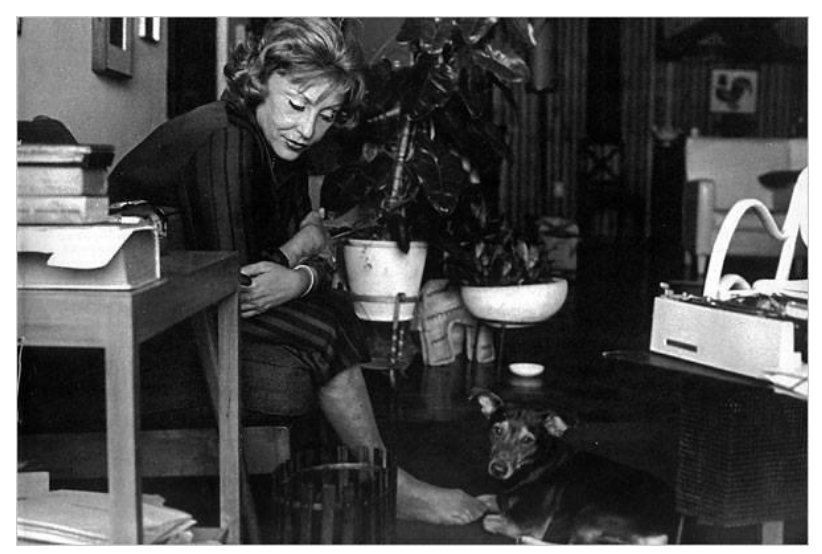

Figura 2: Clarice Lispector e Ulisses ${ }^{5}$

Esta conexão de Clarice com seu cachorro mostra decerto uma busca pela simplicidade, pelo banal. A língua inventada de Ângela, traduzida em Prazer, revela, portanto, a busca de uma pessoa por simplesmente sentir, mesmo que para isso a compreensão humana seja colocada de lado. Pois, para Clarice, o mais importante não era entender ou ser entendida, mas sim sentir o indizível, escrevendo-o ainda que extenuada.

Nesse viés, a percepção de ficar sendo, de Ângela Pralini, em Um sopro de vida, demonstra uma relação com Lóri em Uma aprendizagem. Em convívio com o seu amante Ulisses, Lóri entende que está sendo, e se vê fascinada pelo encontro de si mesma, como um grande passo na aprendizagem que está disposta a atreverse. Esse entendimento também é levado ao palco por meio de Isadora, do espetáculo Prazer. Ao recordar um

5 Imagem obtida por meio do site Saraiva Conteúdo. Disponível em: <http://www.saraivaconteudo.com.br/Materias/Post/42523>. Acesso em: 18/11/2014. episódio em que, certa vez, viu dois cegos comendo despretensiosamente, Isadora reflete - olhando-se ao espelho enquanto retira a sua maquiagem - acerca da máscara social que muitos humanos forjam para viver sob as aparências. Para ela, a maior evidência disso se dá quando as pessoas se veem ao espelho, fazendo este senso narcisista aflorar. Isadora então imagina que nos animais não há esse problema, pois eles se ocupam apenas em estar sendo, e presume que até mesmo o pavão, ao se exibir, talvez não possua esta consciência exibicionista própria dos humanos.

Esta cena (do espelho) acontece no espetáculo em decorrência de outra, quando Isadora se mostra desejosa de aprender algo sobre si, de se transformar. Ela conta que, certo dia, ao perder um par de sapatos, fez uma pergunta a si mesma, como sempre fazia quando perdia algo: "se eu fosse eu, onde é que os teria guardado?". Mas, desta vez, o "se eu fosse eu" desencadeou nela uma potente revelação íntima:

Se eu fosse eu de verdade, talvez nem
os meus amigos conseguissem me
reconhecer na rua, talvez até a minha
fisionomia ia mudar. Foi o que eu
consegui responder no espanto, mas
depois não consegui responder mais
nada, era como se a mentira em que
eu vivia acabasse de ser ligeiramente
tocada, deslocada. E a partir daí eu
não podia mais mentir, pelo menos pra
mim mesma. Eu não podia mais
mentir. Acho que foi nessa hora que
eu virei uma pergunta. (13:32min)

6 Disponível em: <https://www.youtube.com/watch?v=5x8KYhYIW4>. Acesso em 10/05/2015. 
Em Prazer, a máscara que Isadora utiliza para se representar aos poucos vai se esvanecendo. Esse processo é representado no palco por meio da ação da personagem ao retirar a maquiagem ao espelho. Pode-se entender essa cena como tradução criativa em Prazer a partir da máscara de Lóri, com todas as potencialidades poéticas e simbólicas em Uma aprendizagem, pois a máscara (maquiagem) de Lóri também vai se dissolvendo aos poucos como uma lama seca:

É que, depois de anos de relativo sucesso com a máscara, de repente ah menos que de repente, por causa de um olhar passageiro ou de uma palavra ouvida do chofer - de repente a máscara de guerra da vida crestavase toda como lama seca, e os pedaços irregulares caíam no chão com um ruído oco. $E$ eis rosto agora nu, maduro, sensível quando já não era mais para ser. $\mathrm{E}$ o rosto de máscara crestada chorava em silêncio para não morrer. (LISPECTOR, 1998, p. 87)

Ainda, a fala de Isadora do se eu fosse eu revela ser uma tradução criativa de outro trecho de Uma aprendizagem, quando a professora Lóri procura pela prova de seu melhor aluno e não a encontra. $O$ que se faz apropriado questionar: Lóri - assim como Isadora com seus sapatos - não consegue encontrar a prova, ou a si mesma?

A procura se tornava inútil. Então ela se perguntou, como antes fazia, já que perdia tanto as coisas que guardava: se eu fosse eu e tivesse um documento importante para guardar que lugar eu escolheria? $\mathrm{Na}$ maioria das vezes isso a guiava a achar 0 perdido. Mas desta vez ficou tão pressionada pela frase "se eu fosse eu" que a procura da prova se tornara secundária, e ela começava sem querer a pensar, o que nela era sentir. E não se sentia cômoda. "Se eu fosse eu" provocara um constrangimento: a mentira em que se havia acomodado acabava de ser levemente locomotiva do lugar onde se acomodara. [...] Lóri achava que se ela fosse ela, os conhecidos não a cumprimentariam na rua porque até sua fisionomia teria mudado. "Se eu fosse eu" parecia representar o maior perigo de viver, parecia a entrada nova do desconhecido. (LISPECTOR, 1998, p. $128,129)$

Lóri tem medo de se adentrar no desconhecido caminho de sentir-se feliz. Felicidade refere-se aqui a uma estranha paz intensa, o que faz Lóri experimentar um profundo estado de angústia, a ponto de se transformar em dor. Por isso que, inicialmente, a protagonista clariceana prefere a mediocridade em relação à vida. Porém, algo começa a transformar em sua vida, assim como acontece com Isadora. Portanto, o autoquestionamento "se eu fosse eu?" levanta em Isadora e em Lóri algo muito maior: expõe uma dor que a princípio elas tentam ocultar, amenizar, mas que sempre se encontra latente. A pergunta evidencia assim uma mentira de vida, de ter que esconder seus rostos com uma máscara que elas mesmas criaram, a fim de se abrigarem da dor do mundo por meio da mediocridade. Entretanto, como visto, tais máscaras começam a se esfarelar devido à procura pela aprendizagem de si mesmas. Elas almejam entrar no que é desconhecido, procurando por uma transformação de vida. 


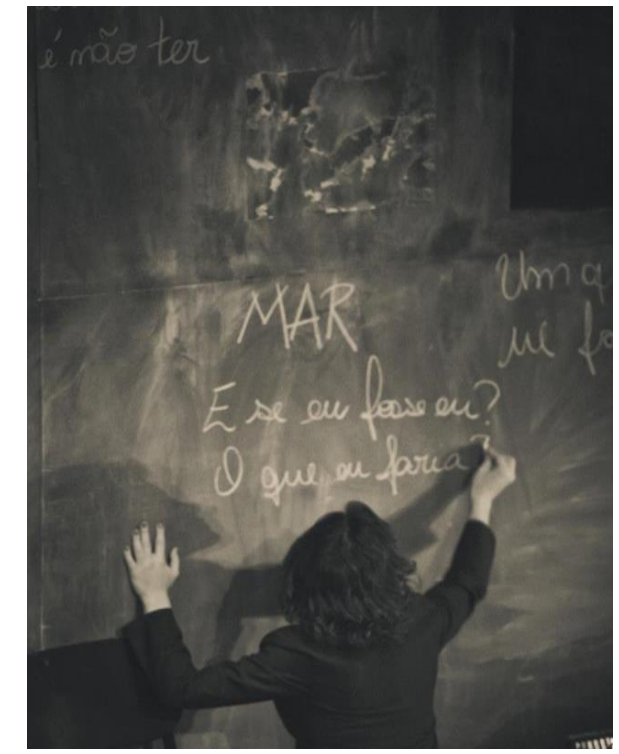

Figura 3: Isadora e a questão "E se eu fosse eu?"7

Ainda, a tradução criativa entre estas duas obras artísticas, objetos deste estudo, pode também ser observada na cena do Sou vigorosa, de Prazer, em que Marcos busca confortar Isadora, devido às constantes incertezas e conflitos que a personagem está passando. Marcos pede para que Isadora pense em algo bom, e ela responde ser o mar. Ele segura então a sua palma da mão com a dela, e em um movimento enérgico para cima e para baixo, repetem diversas vezes em voz alta, como se fosse um mantra: "Sou vigorosa! Sou vigorosa! Sou vigorosa..." (PRAZER, 2013, 1:16:18). Isabela Paes (2013) revela, em entrevista a esta pesquisa, que essa cena foi criada a partir da prece de Lóri em Uma aprendizagem. Durante o processo criativo de Prazer, a atriz considerava esta prece como um material digno de ser citado na íntegra no espetáculo, mas que acabou não acontecendo.

7 Imagem obtida por meio da página da Cia. Luna Lunera no Facebook. Foto: Adriano Bastos. Disponível em: <http://facebook.com/cia.lunalunera>. Acesso em: $14 / 08 / 2014$.
Entretanto, a cena em que Marcos pede o máximo de Isadora em um momento difícil pode ser entendida, de acordo com Paes (2013), como uma tradução de quando, em Uma aprendizagem, Ulisses pede o mesmo à Lóri. Esse pedido faz com que Lóri se sinta instigada a buscar - por meio de um Deus, ou de seu mais profundo eu - uma alegria modesta e diária, a fim de lhe resguardar de toda dor da angústia:

Alivia a minha alma, faze com que eu sinta que Tua mão está dada à minha, faze com que eu sinta que a morte não existe porque na verdade já estamos na eternidade, faze com que eu sinta que amar é não morrer, que a entrega de si mesmo não significa a morte, faze com que eu sinta uma alegria modesta e diária, faze com que eu não Te indague demais, porque a resposta seria tão misteriosa quanto a pergunta, faze com que me lembre de que também não há explicação porque um filho quer o beijo de sua mãe e no entanto ele quer e no entanto o beijo é perfeito, faze com que eu receba o mundo sem receio, pois para esse mundo incompreensível eu fui criada e eu mesma também incompreensível, então é que há uma conexão entre esse mistério do mundo e o nosso, mas essa conexão não é clara para nós enquanto quisermos entendêla, abençoa-me para que eu viva com alegria o pão que eu como, o sono que durmo, faze com que eu tenha caridade por mim mesma pois senão não poderei sentir que Deus me amou, faze com que eu perca o pudor de desejar que na hora de minha morte haja uma mão humana amada para apertar a minha, amém. (LISPECTOR, 1998, p. 56)

Ao fazer essa prece, Lóri entende que há um caminho a ser percorrido, se agir da melhor forma possível, isto é, dar o seu máximo para

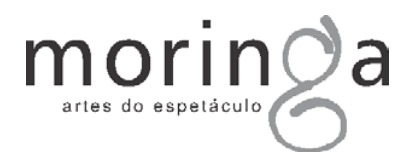


si mesma. E ainda compreende que quando estivesse pronta, poderia dar o máximo de si aos outros também. Mas, para isso, Lóri precisaria primeiramente tocar em si mesma, no sentido de se entender, para que depois pudesse tocar no mundo. Relacionando o trecho de Lóri com a cena do Sou vigorosa, do espetáculo Prazer, pode-se perceber que ambas as obras artísticas estão em busca de um caminho. E que é necessário percorrê-lo, a fim de entender por que o sofrimento é necessário, de entender como é possível viver apesar de.

\section{Considerações finais}

Pode-se observar que tanto os personagens clariceanos, quanto os personagens de Prazer estão em busca de um caminho com o propósito de compreender a si mesmos e o mundo. $E$ isso se torna evidente também devido aos estudos realizados aqui, pois, entende-se que há em Prazer uma reverberação de múltiplos sentidos a partir da vida e obra de Clarice Lispector. Assim, a estrutura de signos clariceanos possui relações recíprocas com os signos presentes no espetáculo Prazer, mesmo que este seja uma obra autônoma, pois Clarice serviu como uma importante inspiração para a livre criação dos atores-codiretores.

Portanto, a tradução criativa observada em Prazer a partir de Clarice Lispector não acontece na íntegra, mas por meio da essência clariceana em consonância e ressonância com o fazer artístico próprio da Cia. Luna Lunera. Utiliza-se aqui o termo essência não no sentido ontológico da palavra, mas no sentido de ser uma existência, uma presença. Como se fosse um aroma (perfume) que, atravessando espaços, deixa rastros.

Recebido em: 25/10/2017

Aceito em: 29/01/2018

\section{Referências Bibliográficas:}

CAMPOS, Haroldo de. A arte no horizonte do provável e outros ensaios. São Paulo: Perspectiva, 1969.

CAMPOS, Haroldo de. Da tradução como criação e como crítica. In: Metalinguagem e outras metas. 4. ed. São Paulo: Perspectiva, 2010.

CIA. LUNA LUNERA. Luna Lunera Companhia de Teatro. Disponível em: $<$ ttp://cialunalunera.com.br/>. Acesso em 10/05/2015.

DINIZ, Thaís Flores Nogueira. A Tradução Intersemiótica e o conceito de equivalência. In: Revista Brasileira de Literatura Comparada - ABRALIC, São Paulo, v. 2, p. 1001-1004, maio 1994.

LISPECTOR, Clarice. Quase de verdade. Rio de Janeiro: Rocco, 1999.

LISPECTOR, Clarice. Um sopro de vida. São Paulo: Círculo do Livro, 1978.

LISPECTOR, Clarice. Uma aprendizagem ou o livro dos prazeres. Rio de Janeiro: Rocco, 1998.

PAES, Isabela. Entrevista sobre o espetáculo Prazer. Belo Horizonte, 11 dez. 2013. Entrevista concedida a Danilo França do Nascimento.

PAVIS, Patrice. Dicionário de teatro. Trad. J. Guinsburg e Maria Lúcia Pereira (org.). 2. ed. São Paulo: Perspectiva, 2005.

PLAZA, Julio. Tradução intersemiótica. São Paulo: Perspectiva, 1987.

SANTAELLA, Lucia. Semiótica aplicada. São Paulo: Cengage Learning, 2010. 